\title{
NORM AND NUMERICAL RADIUS INEQUALITIES FOR A PRODUCT OF TWO LINEAR OPERATORS IN HILBERT SPACES
}

\author{
S.S. DRAGOMIR
}

Abstract. The main aim of the present paper is to establish some norm and numerical radius inequalities for the composite operator $B A$ under suitable assumptions for the transform $C_{\alpha, \beta}(T):=$ $\left(T^{*}-\bar{\alpha} I\right)(\beta I-T)$, where $\alpha, \beta \in \mathbb{C}$ and $T \in B(H)$, of the operators involved.

Mathematics subject classification (2000): Primary 47A12, 47A30; Secondary 47A63.. position..

Keywords and phrases: Bounded linear operators, Numerical radius, Operator norm, Cartesian decom-

\section{REFERENCES}

[1] S.S. DRAGOMIR, Reverse inequalities for the numerical radius of linear operators in Hilbert spaces, Bull. Austral. Math. Soc., 73 (2006), 255-262.

[2] S.S. DRAGOMIR, A survey of some recent inequalities for the norm and numerical radius of operators in Hilbert spaces, Banach J. Math. Anal., No. 2, 1 (2007), 154-175, [Online http://www.mathanalysis.org/].

[3] S.S. DRAGOMiR, New inequalities of the Kantorovich type for bounded linear operators in Hilbert spaces, Linear Alg. App. 428 no. 11-12 (2008), 2750-2760.

[4] S.S. DRAGOMIR, Some inequalities of the Grüss type for the numerical radius of bounded linear operators in Hilbert spaces, J. Inequal. Appl. 2008, Art. ID 763102, 9 pp.

[5] W. GReub AND W. Rheinboldt, On a generalization of an inequality of L. V. Kantorovich, Proc. Amer. Math. Soc., 10 (1959), 407-415.

[6] K.E. Gustafson and D.K.M. Rao, Numerical Range, Springer-Verlag, New York, 1997.

[7] P.R. Halmos, A Hilbert Space Problem Book, second edition, Springer-Verlag, New York Heidelberg Berlin, 1982.

[8] F. KitTANEH, A numerical radius inequality and an estimate for the numerical radius of the Frobenius companion matrix, Studia Math., 1581 (2003), 11-17.

[9] F. Kittaneh, Numerical radius inequalities for Hilbert space operators, Studia Math., 1681 (2005), $73-80$. 